\title{
Linhagens e perspectivas: a saúde na América Latina
}

\author{
Luiz Antônio de Castro Santos \\ Sociólogo e professor adjunto do \\ Instituto de Medicina Social da UERJ \\ Rua Felício dos Santos, 62 \\ 20240-240 Rio de Janeiro - RJ \\ e-mail: LACS@Uerj.Br
}

\begin{abstract}
"Show us a community wallowing in vice, whether from the pamperings of luxury or the recklessness of poverty, and we will show you that there truly the wages of sin are death. Point out the government legislating only for a financial return, regardless or ignorant of the indirect effects of their enactments, and we shall see that the pieces of silver have been the price of blood."
\end{abstract}

Robert Ferguson, 1840

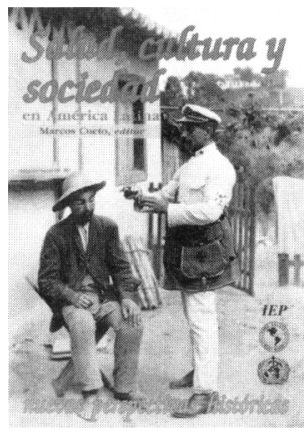

Marcos Cueto (org.) Salud, cultura $y$ sociedad en América Latina: nuevas perspectivas bistóricas Lima, Instituto de Estudios Peruanos/ Organização Pan-Americana de Saúde, 1996
$\mathrm{U}$ ma coletânea de artigos é sempre difícil de resenhar, pois reflete invariavelmente uma forte tensão entre a diversidade de perspectivas dos autores e a unidade temática que o organizador deseja, a custo, preservar. Mas a Introdução facilita minha tarefa: feita com clareza e domínio do tema, traça um amplo painel dos estudos históricos da saúde na América Latina e apresenta, nas notas, uma copiosa bibliografia. Desse modo, antecipa ao leitor as ferramentas necessárias para lidar com a diversidade. Cada capítulo pode, então, ser lido a partir das preciosas indicações de Marcos Cueto.

A Introdução propõe distinguir "a saúde na história" e "a história da saúde". O primeiro termo corresponde aos processos e rupturas vividas pela saúde na América Latina desde o século XVIII; o segundo abarca, como o primeiro, alguns estudos exemplares, mas a atenção concentra-se nos paradigmas e linhagens a que se filiam tais estudos e que demarcam um campo intelectual. A análise é esclarecedora. Cueto distingue aqui três territórios, um primeiro, ocupado pela historiografia tradicional, freqüentemente de cunho hagiológico; um segundo, constituído por estudos institucionais, que privilegiam as relações entre as instituições de saúde e as estruturas econômicas e políticas; um terceiro, em formação e de maior complexidade, sob o impulso de jovens historiadores sociais latino-americanos.

Parece-me, entretanto, que outros recortes seriam mais condizentes com a própria concepção da obra e permitiriam entender melhor o contorno das linhagens e identidades intelectuais. Um primeiro recorte, que não se aplica a qualquer dos textos que compõem esta obra coletiva, abrange estudos que tomam a saúde e a medicina como pretexto. Tocarei neste ponto porque esta posição instrumental se aplica a boa parte da literatura latino-americana sobre saúde. 
Este tipo de abordagem inclui a crônica sobre os grandes feitos da medicina, em que o historiador "distribui prêmios e penas aos heróis defuntos".' Médicos e sanitaristas transformam-se em modernos taumaturgos ou falsos profetas, conforme o juízo moral do cronista. Mas incluem-se, sobretudo, estudos que tomam a medicina e a saúde como epifenômenos de relações de produção, e textos que interpretam as assistências médica, sanitária e social como estratégias estatais de 'colonização' e medicalização dos corpos. No primeiro caso, estamos diante do marxismo vulgar, em que dados históricos são manipulados por explicações ad hoc. O esquematismo das interpretações compromete o esforço gigantesco de se traçar análises macrohistóricas da medicina estatal latino-americana, como ocorre, a meu ver, na obra fecunda de Juan César García. Já na tese da medicalização, o olhar foucaultiano torna-se uma camisa-de-força, à qual a história do Estado, das políticas estatais e do cotidiano das sociedades da América Latina submetese de modo implacável. ${ }^{2}$

Como lembraria Florestan Fernandes, não é raro defrontarmos com o emprego de teorias "como forma rígida de ortodoxia", não como orientação metodológica. ${ }^{3}$ A teoria deve ser um compromisso, uma idéia reguladora. ${ }^{4}$ Se vemos nela um objeto de adesão incondicional, deixa então de ser reguladora para ser disciplinadora. A análise histórica, ao invés de refletir um balizamento metodológico, revela-se um pretexto para a demonstração de ortodoxias.

Quanto à historiografia tradicional, esta nos coloca ante uma situação de aparente paradoxo, a cega observância de cânones que os próprios cronistas desconhecem. Seguem burocraticamente a historiografia "dos grandes feitos", por tradição, não por adesão consciente. Se eu tivesse que avaliar as três posiçôes metodológicas, a historiografia tradicional estaria em desvantagem frente às demais. Como diria Italo Calvino, a pior ortodoxia ainda é melhor do que a escravidão a regras que se ignora.

Faço estas considerações no intuito de indicar que os sinais de "novas perspectivas", apontadas na Introduçào, podem ser enganosos. Cueto enaltece, em particular, as obras contemporâneas, que esquadrinham o cotidiano das classes populares e sua capacidade de luta e negociação diante das questões da saúde. Entretanto, a tentativa de resgatar as camadas populares como "sujeitos ativos" (p. 26) e produzir uma historia "desde abajo" pode cair nos esquematismos doutrinários a que me referi. Creio ser esta a fragilidade de alguns estudos sobre a chamada Revolta da Vacina, no Rio de Janeiro, em 1904. Até que ponto o povo realmente se sublevou especificamente "contra a vacina"? Pode-se argumentar que, sem a resistência das pessoas à vacinação, o movimento não teria assumido maiores proporções. Mas uma coisa é a manipulação, por parte das oligarquias dissidentes, da contrariedade das massas. Outra coisa é ver na rebeliào, a meu ver erradamente, um indício do surgimento de uma luta por direitos civis da saúde. ${ }^{6}$ Interpretações que procurem atribuir às manifestações do povo carioca contra a vacinação obrigatória um despontar de "sujeitos ativos diante das políticas de saúde" não estarão forçando a mão? Se a historiografia das lutas populares por melhores condições de trabalho encontra na Primeira República um terreno fértil, tal não se dá com as condições de saúde. Para avaliar em que medida o Brasil do início do século teve atores populares ativos neste campo, a nova historiografia terá de avaliar se as manifestações 
e rebeliões dos vencidos conduziram, concretamente, à formação de estratégias de organização política em torno da saúde. De que modo afetaram - ou afetariam - as políticas públicas no campo da higiene? Qual foi a participação popular na criação de frentes de luta pelo saneamento? Pareceme que somente uma boa dose de wishful thinking permitirá vincular as lutas operárias às origens das políticas de saúde no Brasil. Não estamos, ainda uma vez, na presença de uma leitura dos fatos históricos que é pretexto para explicações ad boc?

Um segundo recorte caracteriza e valoriza a totalidade dos trabalhos históricos incluídos em Salud, cultura y sociedad. Ao invés de pretexto para defesa de um motto ou bead-motif, os artigos estabelecem com a história da saúde um diálogo tenso, cujo desfecho não se pode antecipar, mas deriva do duro embate com o material histórico. Em cada capítulo, os documentos compõem a difícil trama que se vai tecer a partir de idéias diretoras ou reguladoras (A. Heller). Estas idéias conduziram seus autores à escolha do recorte analítico - e à própria seleção dos documentos —, mas estes não se curvam, dóceis, à tarefa de composição. Se tivesse que definir a principal qualidade desta coletânea, não hesitaria em apontar em todos os textos, sem exceção, a presença do trabalho empírico vigoroso e criativo.

No Apêndice que fecha o volume, Cueto e Birn parecem ter visto nesta qualidade um reflexo da influência da Escola dos Annales, por causa de os jovens historiadores da saúde terem dado prioridade "a novas dimensões do estudo do passado", ou por recapturarem "a evolução dos setores populares" etc. (p. 237). A história da saúde teria só recentemente incorporado, "de modo geral, este enfoque de história social". Esta é uma questão complexa e importante, pois demarca as raízes e opções de nosso campo intelectual.

No meu entender, a história da saúde mais recente alinha-se a tendências e opções de pesquisa muito mais antigas do que os Annales. Não se trata de negar sua influência, mas de postular, mesmo na historiografia mais recente, uma continuidade fundamental em relação às preocupações da medicina social do século XIX e da demografia histórica (a "aritmética política") do século XVIII. Penso nas concepções de Virchow sobre "reforma médica" como reforma essencialmente política, concepções lembradas por George Rosen em texto famoso, ${ }^{7}$ penso nas bills of mortality de Londres e das colônias, desde os séculos XVII e XVIII, que municiavam estudos nos quais as classes populares e seu cotidiano de doença, trabalho, miséria e "desregramentos" se viam retratados. ${ }^{8}$ Penso, também, na copiosa produção de intelectuais, juristas, médicos e engenheiros que, desde o início do século XIX, escreviam em periódicos britânicos como a Westminster Review e a Edinburgh Review; nos Public Health Reports do governo inglês, que Marx consultou, minuciosamente, para denunciar os níveis de vida dos trabalhadores." A epígrafe que selecionei, de autoria do obstetra da rainha Vitória, Robert Ferguson, traduz o interesse que médicos "especialistas" da época tinham nos aspectos sociais e políticos da saúde pública. ${ }^{10}$ Deste interesse pelos níveis de vida e pelas condições de saúde de trabalhadores, pela questão do trabalho infantil, pela alta mortalidade que vitimava as crianças, despontou o monumental Report on the sanitary condition of the labouring population of GreatBritain, publicado por sir Edwin Chadwick, em 1842. Engels baseouse largamente nesta obra, bem como em outros relatórios das "leis dos pobres", para produzir seu famoso livro sobre a condição da classe operária na Inglaterra. 
Faço estes comentários com o único propósito de sugerir que a 'nova' história da saúde, na verdade, nada tem de nova. Suas raízes são muito antigas e vão buscar não neste, mas em séculos passados, a seiva verdadeiramente formadora. Se houve uma ou outra vertente de produção historiográfica e sociológica que se afastou daquela tradição, seja congelando-a sob uma armação estruturalista, seja dissolvendo-a nas minudências da historiografia reverencial, nem por isso parece-me acertado recusar à história da saúde sua própria história, e atribuir sua evolução a um movimento tão recente como os Annales.

Os trabalhos reunidos em Salud, cultura y sociedad estão, todos, fincados naquela tradição dos estudos históricos a que me referi, rica e multissecular, abordada como processo amplo, contraditório e dinâmico. Cabe-me, agora, comentar rapidamente cada um dos capítulos à luz desta sugestão inicial. Desde logo, devo ao leitor uma palavra de encorajamento: diferentemente desta resenha, que tarda em 'chegar ao ponto', os textos, escolhidos com maestria pelo organizador, caracterizam-se por uma capacidade invejável de propor seus temas específicos, esboçar suas teses e defendê-las com empenho. Vamos a elas.

O livro abre com um artigo de Julyan $G$. Peard sobre a chamada Escola Tropicalista Baiana, grupo de médicos pesquisadores que, numa província nada "periférica" para a medicina brasileira, marcou a segunda metade do século XIX com contribuições pioneiras. Num primeiro olhar, brotava ali uma ciência 'dependente', na periferia da periferia do capitalismo internacional. Entretanto, Peard conta-nos outra história: poucos até hoje exploraram "la posibilidad que dentro de la tradición médica latinoamericana hubiesen corrientes relativamente independientes" (p. 33). Idéias como a propalada "especificidade" de certas enfermidades foram questionadas pioneiramente por este grupo de médicos residentes na Bahia. Precedendo os higienistas europeus, o luso-germânico-'baiano' Otto Wucherer lembrava que a anemia que vitimava os operários na construção do túnel de São Gotardo, na Suiça, em 1880-82, era causada pelo ancilóstomo que se julgava existente apenas nos trópicos. Por outro lado, para o grupo tropicalista a tuberculose não era um mal "europeu", mas também atacava abaixo do equador. Em segundo lugar, Peard mostra que fomos, sim, modernos. As correntes explicativas ambientalista e parasitária tiveram, junto a estes primeiros tropicalistas, uma convivência íntima.

Um problema que a meu ver exige pesquisa de tipo etnográfico é o das relações dos tropicalistas baianos com o mundo da província e do país. $O$ pouco conhecimento sobre o alcance real das interações e negociações entre o grupo de higienistas e os círculos mais amplos da medicina baiana e brasileira daquela época, e sobre a efetiva criação de 'herdeiros' intelectuais, põe dificuldades para que continuemos a denominar 'escola' um grupo que, talvez, não tenha propriamente feito escola.

Esta base empírica ainda frágil parece explicar a ambigüidade de algumas conclusões de Peard: ora chama a atenção para o fato de que jamais chegaram a ser professores da Faculdade de Medicina da Bahia e tampouco receberam apoio institucional para suas pesquisas (pp. 37-8); ora indica que teriam sido responsáveis, ainda assim — por terem trabalhado no Hospital da Santa Casa da Misericórdia e por terem fundado a Gazeta Médica da Babia -, pela promoção da "idea de una nación brasileña progresista" (p. 40); 
mas lembra que, a partir de 1885, deixaram de formar "um grupo claramente definido", não formaram discípulos, e não lograram "institucionalizar por completo su temprano ideal de una medicina e investigación pura en los trópicos" (p. 51). A institucionalização do ideal bacteriológico, sugere Peard, deu-se apenas quando Oswaldo Cruz, "sob el contexto político relativamente tranquilo de la Vieja República" (p. 52), pôde fazer uso dos esquemas de financiamento governamental à pesquisa científica. Ocorre aí um problema na construção do argumento: primeiramente, o contexto político estava longe, muito longe, de ser "tranquilo". Mas, fosse ou não tranqüilo o ambiente político, no início da República é que se deram os primeiros passos firmes da reforma da saúde pública e da pesquisa experimental no país. Que o Distrito Federal e o estado de São Paulo tenham liderado este processo e que a Bahia tenha ficado para trás (apesar do "legado tropicalista"), eis uma questão crucial que Peard não chega a contemplar. ${ }^{11}$

O artigo de Jaime L. Benchimol, "Domingos José Freire y los comienzos de la bacteriología en Brasil", apresenta-nos, por meio de uma microhistória densa e envolvente, o cenário das pesquisas e das campanhas de vacinação popular contra a febre amarela encetadas, nas décadas de 1880 e 1990, por um "homem de ciência" quase delirante. Benchimol nào escreve para adeptos de uma sociologia de ciência desencarnada. Muito ao contrário, sua cativante narrativa nos transforma em partícipes do drama humano de Domingos José Freire. O modo pelo qual Freire se distanciava dos pares à medida que suas descobertas e sua vacina antiamarílica — com a qual inoculou quase $13 \mathrm{mil}$ pessoas! - eram contestadas no Brasil e no exterior; as lutas para recuperar junto à população e à imprensa do Rio de Janeiro a legitimidade que perdera na Academia; a auto-imagem ora reconstruída, ora em frangalhos. Estamos diante de um campo de batalha, não de uma 'comunidade' científica. Benchimol refere-se à "imagem beligerante" de Domingos José Freire, à "individualidade providencial" - sua crença num papel messiânico perante a humanidade, liberta para sempre da febre amarela pela graça da "vacina Freire". Não sei se a trajetória de vida lembra um Antônio Conselheiro da ciência, como chegou a ser chamado, ou, talvez, um certo Cavaleiro da Triste Figura. Milhares deram a vida para seguir Antônio Conselheiro, mas Domingos Freire morreu desoladamente só, sem seguidores. Benchimol mostra que bastou pouco para silenciá-lo: uma carreira solo. O que pôs fim às polêmicas sobre suas descobertas foi, simplesmente, "a morte do descobridor" (p. 83). Não por acaso, foram necessários talento e método para recuperar a saga deste homem que, talvez por não ter originado uma 'linhagem', nunca chegou a transformar-se em mito da ciência brasileira e nem sequer ganhou a fria notoriedade dos compêndios de história da medicina.

Lilia V. Olivier focaliza um tema regional - a ocorrência da cólera em Guadalajara -, e faz dele um interessante ponto de partida para uma comparação histórico-sociológica, ao focalizar dois surtos epidêmicos, em 1833 e 1850. A análise comparativa se faz, portanto, ao longo do tempo, no mesmo espaço urbano. O fator espacial, digamos, não varia. A questão que formula, "Por que a cólera foi menos agressiva em 1850 do que em 1833, em Guadalajara?" (p. 103), torna-se mais atraente em face da informação da autora, de que as condições de vida na cidade teriam sofrido um agravamento ao longo do período. Daí se poderia esperar que a epidemia se abatesse com maior, e não menor, força sobre a população. A autora trabalha muito 
bem com a análise demográfica, mas dali não resulta, infelizmente, uma resposta satisfatória para a questão comparativa que sublinhei anteriormente. Sob outro ângulo, Lilia Olivier conclui que epidemias como as que atingiram o México no século XIX provocaram um tipo de política sanitária regionalizada, que procurava minorar os problemas nas áreas mais atingidas. A autora vê neste padrão de 'municipalização' a etapa inicial do desenvolvimento dos serviços de saúde pública em outros países da América Latina, mas, cautelosa, propõe que este tema venha a merecer a atenção de estudos comparativos. O caso mexicano, também estudado por Birn na presente coletânea, parece confirmar sua hipótese. Somente muito mais tarde, com o código sanitário de 1926 , os serviços de saúde locais foram subordinados ao poder central (p. 205, capítulo redigido por Anne-Emanuelle Birn).

Os três capítulos que se seguem são intimamente interligados. $O$ historiador Diego Armus trabalha com saúde e anarquia na Argentina, e a tuberculose é o elo entre os dois termos; as sociólogas Nísia Trindade Lima e Nara Brito trabalham com saúde e nação no Brasil, e as chamadas "endemias dos sertões" (malária, ancilostomíase e doença de Chagas) são os elementos da expressão; a historiadora Diana Obregón focaliza a interface entre saúde e profissão médica na Colômbia, sendo a lepra seu objeto central. São artigos admiráveis, sob muitos aspectos. Demonstram a intensa politização das questões da saúde desde o final do século passado até pelo menos 1930 no Brasil e 1940 na Argentina e Colômbia, envolvendo toda a população e, em particular, as elites intelectuais e profissionais (Brasil e Colômbia) e os setores obreiros anarquistas (Argentina).

Os temas da miscigenação, da eugenia e da harmonia social e racial, ainda que com peso diferente em cada país, permearam o debate nacional e tiveram um importante denominador comum: acrescentaram ao binômio saúde e política o terceiro termo 'raça'. Armus esclarece um ponto nebuloso: nem sempre a noção de raça teve entre os sul-americanos um significado lamarckista, pois, "entre fines del siglo XIX e comienzos del XX, era una categoría extremamente laxa y que entre los libertarios tendía a asimilarse con 'el pueblo'" (p. 115). Talvez a acepção eugênica fosse mais acentuada entre colombianos e brasileiros, como se depreende do artigo de Diana Obregón e da obra recente do antropólogo Sérgio Carrara. ${ }^{12}$ Mas estes aspectos devem ser enfatizados: a tuberculose ligou-se à discussão política $e$ racial na Argentina, as "grandes endemias dos sertões" provocaram o debate no Brasil e a lepra catalisou a luta pela reforma sanitária na Colômbia. O que parece indicar que, em lugar de buscarmos em uma única doença a causa da grande politização da saúde, devemos estar atentos ao modo concreto com que, em cada região, uma determinada enfermidade ou um conjunto delas se correlacionaram aos rumos da política, do projeto racial e de construção nacional. Se perdermos de vista certos elementos estruturais, talvez nos escape o porquê da relevância desta ou daquela enfermidade: por exemplo, a presença da tuberculose como endemia das grandes cidades talvez explique sua força simbólica num país como a Argentina, cuja população urbana beirava os trinta por cento já em 1895 (Buenos Aires era a cidade mais populosa da América Latina, com 664 mil habitantes e $17 \%$ da população do país). Lembremos, por contraste, o caráter rural da malária e de outras endemias brasileiras no início do século, e o predomínio da população rural sobre a urbana; na Colômbia, onde também era inexpressiva a população urbana, a 
lepra, de face predominantemente rural, assumiu naquele país, como a malária ou a doença de Chagas para os brasileiros, uma face simbólica e política. ${ }^{13}$

O texto de Trindade Lima e Brito pede um comentário sobre o binômio saúde e nation-building. Houve uma estreita ligação entre a ideologia da nação forte, "eugênica e civilizada", e o movimento sanitarista. Lembremos a ação de um Olavo Bilac, poeta/agitador, cujos discursos patrióticos, em 1915, levavam o povo a aderir à causa do saneamento, da educação, do eugenismo etc. ${ }^{14}$ Como bem demonstram as autoras, a Liga Pró-Saneamento e sua revista Saúde derivaram sua força daquele movimento mais amplo em todo o país.

Mas as ações governamentais concretas - digamos, a reforma Carlos Chagas de 1920 - obviamente ligaram-se a fatores conjunturais que têm de ser explicitados em cada caso, e que só indiretamente refletiram os rumos gerais do movimento que unia saúde e nação. Faço este comentário com o propósito de evitar conclusões apressadas do texto. Se o fizéssemos, cairíamos no erro de interpretação que vê em toda política sanitária a ação ardilosa do capitalismo. Seria o mesmo que substituir, de modo simplista, "capitalismo" por "nação". Mas creio que existe consenso, hoje, em torno da idéia de que a reforma sanitária, em sentido amplo, recebeu um notável impulso do "novo nacionalismo" brasileiro de que nos falou Thomas Skidmore.

A questão nacional remete ainda ao texto de Diana Obregón. Mas, antes, uma explicação: a autora mostra como a elite médica colombiana, em fins do século XIX, adotou o modelo etiológico conhecido como "havaiano", mais facilmente adaptado às antigas posturas coloniais espanholas sobre o isolamento dos leprosos. ${ }^{15}$ As metáforas sobre a lepra - a propagação incontida, a necessidade do isolamento, a imagem de "país leproso" - , a partir de fins do século XIX e até pelo menos a década de 1930, foram forjadas pelos médicos no esforço de fortalecer o poder da profissão sobre as instituições religiosas que cuidavam dos enfermos (p. 173).

Nesse cenário manifesta-se a questão da nacionalidade. A elite médica encontrou aliados na própria oligarquia do café, desejosa de atrair imigrantes europeus para sustentar a economia e raças "superiores" para engordar a auto-estima nacional. Para tanto, limpar a mancha da lepra significava uma tarefa de salvação nacional. O Brasil também viu este filme. Se Miguel Pereira falava do espectro do "grande hospital" em que se transformaria a nação brasileira, José Maria Lombana Barreneche temia, por sua vez, que a Colômbia se convertesse em um "enorme lazareto" (p. 170). Estes termos, devo frisar, eram antes metáforas de mobilização nacional do que reflexos de um temor, pelas oligarquias, de que suas familias seriam tragadas pelo lazareto ou pelo grande hospital. É o caso evidente da lepra. Obregón lembra que os doentes eram, em sua maioria, pobres migrantes rurais, nas cidades, ou se encontravam no interior das populações "coloniais" do campo, excluídas da própria nação. Era uma enfermidade "de gente pobre e 'inferior" (p. 163). Empregada como peça retórica do ideal da nacionalidade, a lepra gerou uma preocupação pela saúde pública "como área de acción importante del Estado y de intervención de los profesionales médicos" (p. 172).

Os capítulos seguintes mantêm o tom geral de discussão das amplas balizas políticas das ideologias e ações de saúde. Mas trazem uma contribuição essencial, pois discutem o papel que as missões médico-sanitárias da Fundação Rockefeller desempenharam entre as décadas de 1910 e 1930, 
em quase toda a América Latina, no combate à ancilostomíase, malária e febre amarela. O primeiro texto tem, justamente, o objetivo mais amplo e é de autoria de Marcos Cueto; o segundo, de Anne-Emanuelle Birn, aborda a experiência mexicana e a ação da International Health Division, em contraponto ao "modelo Cárdenas" dos ejidos e suas unidades sanitárias.

Uma primeira lição se tira destes trabalhos: é difícil falar da formação dos sistemas de saúde e da história das doenças na América Latina neste século sem discutir o papel das missões Rockefeller. Mas muito mais difícil é abordar este tema e ficar a salvo do emprego de conhecidos esquemas interpretativos rígidos ou simplificadores. Cueto e Birn, com maestria, escapam ilesos de tais armadilhas; quem ganha com isso é a história da saúde na América Latina.

Senão, vejamos. A presença do Estado, paradoxalmente fortalecido pela missão norte-americana nos países em que atuou, é destacada com precisão no texto mais geral de Marcos Cueto e no estudo de Birn. Governos como o do Brasil, Colômbia e México desfrutavam, já, de algum progresso na criação de serviços e estruturas administrativas, bem como de uma tradição científica apreciável, anteriores à chegada da Rockefeller (como indicam abundantemente os demais textos da coletânea). Isto facilitou a relação entre as missões e os países receptores. O efeito centralizador das campanhas sanitárias auxiliou os governos em suas "escaramuças" ( $p$. 187) com as municipalidades e as oligarquias rurais.

Ainda que esta última afirmação dê conta do panorama geral, a análise de experiências nacionais concretas aponta, é claro, para variações e singularidades. No caso brasileiro, esta singularidade é muito forte. A centralização dos serviços, em particular, e o fortalecimento do Estado, em sentido amplo, só raramente se deram à custa dos interesses agrários. Quase sempre o que se dava era uma disputa localizada e um acordo generalizado... Quando se aprovava uma legislação mais intervencionista - como o código de higiene rural 'baixado' pelo governo do estado de São Paulo em 1917 -, para permitir que os agentes de saúde entrassem nas fazendas e realizassem inspeções, quem articulava a aprovação da legislação no congresso estadual eram políticos-fazendeiros, todos aliados no interior do tentacular Partido Republicano Paulista (os mexicanos também já viram este filme). No plano nacional, reproduzia-se este jogo de forças em que oligarquias agrárias e Estado procuravam se entender na distribuição dos frutos da modernização 'pelo alto'. ${ }^{16} \mathrm{O}$ que não impediu que se manifestasse um efeito estrutural, não antecipado pelos participantes do jogo político da época - uma tendência geral de fortalecimento dos aparelhos de poder estatal em detrimento das municipalidades.

Cueto faz um apanhado dos problemas enfrentados pela Rockefeller em sua ação internacional. Salvo, talvez, no Brasil, os resultados das campanhas contra a ancilostomíase foram insatisfatórios (p. 188). A luta contra a febre amarela demandou a aplicação, no Brasil, de quase oitenta por cento dos recursos totais, mas foi um fracasso na visão dos próprios dirigentes da fundação (p. 196). As campanhas antimaláricas, ao contrário, tiveram certo sucesso no caso da Argentina, onde a densidade do vetor foi diminuída; mas a erradicação do temido A. gambiae do Nordeste do Brasil, em 1938-40, representou para a Rockefeller seu maior trunfo (pp. 196-9). Um ponto importante é o relacionamento (callous, eu diria) entre o pessoal da Rockefeller, por um lado, e as autoridades governamentais, os técnicos e a 
população dos países latino-americanos. Cueto fala, a propósito, da "poca conciencia por las idiosincracias culturales y la educación de la comunidad, y una participación limitada del personal local en cargos diretivos" (pp. 191-2). Creio que tudo isto se explicava por uma relação de subordinação/dominação em cadeia. As próprias autoridades sanitárias brasileiras também desconsideravam as populações locais, seus modos de vida e representações coletivas. Leia-se, a propósito, o depoimento de um antigo médico da Rockefeller no Brasil (citado por Cueto), que fala da aliança entre Vargas e a Rockefeller durante o Estado Novo e das facilidades daí decorrentes para a imposição, sobre as populações locais, dos serviços de controle dos vetores (p. 194).

Birn sugere que a relação com Cárdenas, no México, sob as pressões do clima político 'ainda' revolucionário, não seguiu o rumo das alianças 'pelo alto'. De toda maneira, os direitos constitucionais da saúde, criados pela Revolução, não teriam tido uma função retórica de mobilização e cooptação, que só nesta medida (da retórica) se chocavam com o enfoque técnico e 'despolitizante' da Rockefeller? Birn fala, no entanto, da "creciente presión popular" por unidades permanentes de saúde e medidas preventivas (pp. 206-22), o que indicaria uma relação singular entre saúde e política no México. O campesinato organizado chegou a contribuir com metade dos custos dos serviços locais de saúde organizados pelo Departamento de Salubridad Pública sem o apoio da Rockefeller (p. 224). Nesse caso, vê-se que as resistências à pedagogia técnico-elitista da Rockefeller se explicam antes por imperativos reais de mudança social do que por um esforço retórico de cooptação, por parte do governo Cárdenas. Modernização desde abajo?

Tudo somado, os dois estudos sobre a fundação norte-americana enfatizam, no legado controvertido das missões, o destaque que davam ao modelo de intervenção 'técnica', com prejuízo de um enfoque educativo e social (Cueto, p. 201; Birn, p. 215). Talvez se possam apontar algumas circunstâncias atenuantes neste impacto sem dúvida alguma 'instrumental': a ênfase da Rockefeller na atividade dos visitadores de saúde; o apoio à formação de carreiras científicas e à dedicação profissional em tempo integral; a valorização da pesquisa e da atividade de campo dos médicos sanitaristas. ${ }^{17}$ Sublinhe-se a olímpica distância (ia escrevendo flexibilidade) política e profissional dos quadros da International Health Division (IHD) em relação ao que se passava em redor, e que lhes garantia, por vezes, a capacidade de se ajustar a situações desfavoráveis e, com isso, fazer prevalecer seu próprio modelo pedagógicocientífico. Anne-Emanuelle Birn relata que, mesmo após a expropriação das empresas petrolíferas por Cárdenas, em 1938, a IHD manteve sua participação nos projetos de saúde no México. Com o tempo, Cárdenas reduziu a tônica governamental sobre as "unidades ejidales" de medicina integral e educativa e obteve o apoio da Rockefeller ao assumir concepções mais técnicas de controle de doenças (pp. 229-31). A especificidade do caminho mexicano cedia lugar, assim, ao modelo adotado em toda a América Latina.

Qual a efetiva responsabilidade da Rockefeller na mudança de rumos da reforma sanitária mexicana? Até que ponto a área da saúde no México e em outros países latino-americanos teve uma dinâmica própria, ou refletiu relações de poder e campos de força exteriores? As respostas colocam-nos forçosamente no terreno da ciência e tecnologia, da política, da economia e da sociedade latino-americanas, do desempenho do Estado, da emergência 
de movimentos sociais com graus variados de autonomia ou dependência em relação às elites. Estes pontos escapam ao foco central da coletânea organizada por Marcos Cueto, que nos reserva, no entanto, um convite a reflexões num outro compasso. Refiro-me ao fecho inesperado do volume, um interessante ensaio curricular com ementas de disciplinas e correspondentes bibliografias, que nos indicam o caminho de novas leituras para fazer face à complexidade dos temas da saúde, cultura e sociedade discutidos na coletânea.

Neste apêndice, Cueto e Birn prepararam o silabo de um Curso de História Social da Saúde Pública na América Latina. Como adiantei, o curso não tem um caráter impositivo, mas meramente indicativo. Louve-se a sutil diplomacia dos organizadores ao procurar reunir, num mesmo tópico, autores e perspectivas nem sempre concordantes, por vezes francamente antagônicos. A proposta do curso é uma iniciativa louvável. Teria apenas uma sugestão, que se soma à montanha das infaliveis 'correções', subtrações e adições que, por certo, muitos já lhes aconselharam: eu acrescentaria dois outros tópicos ao programa, um que abordasse textos básicos de política e economia na América Latina, outro, remetendo a ensaios precursores do pensamento social latino-americano. ${ }^{18}$ Penso em intelectuais do porte de Mariátegui, de José Vasconcelos e Antonio Caso, de Nabuco, Gilberto Freyre e Sérgio Buarque de Holanda. Na obra coletiva que aqui me propus examinar, sempre se revela a preocupação dos autores, cada um a seu modo, com a teia intricada das relações entre saúde e sociedade. O exame de textos clássicos significa repensar tais relações a partir de uma visita às raízes da América Latina.

\section{Notas}

${ }^{1}$ Sérgio Buarque de Holanda (org), 'O atual e o inatual en Lcopold von Ranke'(em Ranke bistónia, São Paulo, Ática, 1979, p. 21) O autor refere-se, aqu, a uma expressão de Marc 13loch, em Apologie pour l'bistoire.

2 Destaco, na bibliografia recente, o excelente ensaio crítico de Maria Helena Souza Patto ('Teoremas e cataplasmas no Brasl monárquico. o caso da medicina socral', Novos Estudos, n* 44, Cebrap, mar. 1996, pp. 180-99), sobre os equivocos da aplicação das idéias de foucault à vida social do Segundo Reinado, no Brasil. Suas crítıas cabem especialmente ao estudo de R. Machado et alı (Danação da norma. Rıo de Janciro, Graal, 1978)

3 Florestan Fernandes, 'O problema do método na explicação sociológica' (em Ensaios de sociologia geral e aplicada São Paulo, Pioneira, 1971, pp 414-5)

4 Agnes Heller, Uma teoria da bistória (trad. D B de Faria Ferreira Lma, Rio de Janerro, Cıvilıação Brasileıra, 1993, pp. 170-3).

${ }^{5} \mathrm{Na}$ presente coletânea, o artıgo de Jaime Benchimol ('Domingos José Freire y los comienzos de la bacteriología en Brasil', pp 53-86) traz à tona a receptividade da população pobre do Rio de Janeiro à prática da vacinação desde a década de 1880 !

${ }^{6}$ Luiz Antônio Teıxeira repõe as questões deste debate em 'A rebelıão popular contra a vacina obrigatória' (Série Estudos em Saíde Coletiva, $\mathrm{n}^{2} 103$, Rio de Janeiro, IMS/OEER, 1994).

7 George Rosen é um estudioso da vida e obra de virchow, um de nossos deuses Penates (ver 'What is social medicine' [A genetic analysis of the concept]', em From medical police to social medicine essays on the bistory of bealth care Nova York, Neale Watson, Science History Publications, 1974) Para exemplificar esta questão da ancestralidade, chamo a atençáo para a referência a Virchow no ensaio de Birn (p 233) 
${ }^{8}$ James H. Cassedy, Demography in early America: beginnings of the statistical mind, 1600-1800 (Cambridge, Massachusetts, Harvard University Press, 1969).

${ }^{9}$ Confronte-se, especialmente, o cap. 25 do primeiro volume de o capital.

${ }^{10}$ Robert Ferguson, 'Public health and mortality' (Quarterly Review, vol. 66, 1840, pp. 115-30). A epigrafe está na p. 116. (O artigo está reproduzido em fac-símile, com cortes, em R. Hodgkinson, Public bealth in the Victorian Age. Vol. I., Westmead, Gregg International Publishers, 1973).

${ }^{11}$ Discuto as posiçôes diferenciadas da Bahia e São Paulo no movimento sanitário brasileiro cm Power, ideology, and public bealth in Brazil: 1889-1930 (Tese de doutoramento, Cambridge, Massachusetts, Universidade de Harvard, 1987). Gilberto Hochman traz uma nova e instigante leitura do movimento da saúde pública nos estados pelo ângulo da interdependência ( $A$ era do saneamento: as bases da politica de satide piiblica no Brasil. Tese de doutoramento, Rio de Janeiro, Iuperj, 1996).

${ }^{12}$ Sérgio Carrara, Tributo a Vênus: a luta contra a sifilis no Brasil, da passagern do século aos anos 40 (Rio de Janciro, Editora Fiocruz, 1996). Nancy Stepan ('Eugenics in Brazil, 1917-1940'. Em Mark 13. Adams lorg.l, The wellborm science: eugenics in Gernany, France, Brazil, and Russia. Nova York, Oxford University Press, 1990) discute profundamente o movimento eugenista no Brasil.

${ }^{13} \mathrm{Na}$ Colômbia, como no Brasil, a população que vivia em cidades naquela época mal chegava a $10 \%$ do total. Ver Nicolás Sánchez-Albornoz (The population of Latin America: a bistory. Trad. W. A. R. Richardson, Berkeley, University of California Press, 1974, tabela 5.13, pp. 178-9).

${ }^{14}$ A "pregação patriótica" de Bilac é discutida por Thomas Skidmore (Black into white: race and nationality in Brazilian thought. Nova York, Oxford University Press, 1974, pp. 152-9)

15 Já havia, mesmo, um lazareto em Cartagena, desde o século XVII. A autora descreve os dois modelos etiológicos e de tratamento, propostos no século XIX: um modelo "democrático" norueguês, que ressaltava o caráter hereditário da enfermidade, bem como fatores ambientais ligados à pobreza e à higiene. Hansen, ao identificar o Mycobacterium leprae, apontou sua natureza contagiosa e passou a defender o isolamento do doente. Ao fazê-lo, aproximou-se do modelo autoritário, contagionista e segregacionista preconizado por médicos europeus no Havaí, onde foi criada a primeira colônia de leprosos, em 1865. Estas explicações estão no texto de Diana Obregón.

${ }^{16}$ Ver nota 10. Uma versão revisada de um capítulo de minha tese encontra-se en 'A reforma sanitária pelo alto: o pioneirismo paulista no início do século $\mathrm{XX}$ ', (Dados: Revista de Ciências Sociais, vol. 36, 3: 361 a 392, 1993).

${ }^{17}$ Ver Lina Rodrigues de Faria ('A fase pioneira da reforma sanitária no Brasil: a atuação da Fundaçào Rockefeller [1915-1930]'. Dissertação de mestrado, Universidade do Estado do Rio de Janeiro, 1994). A formação científica de un Samuel Pessoa, por exemplo, deu-se no interior de um contato estreito com pesquisadores da Rockefeller, como W. G. Smillic.

${ }^{18}$ Cabem, aqui, as sugestôcs do trabalho de Leopoldo Zea (Precursores del pensamiento latinoamericano contemporáneo. México, D. F., Secretaría de Educación Pública/Editorial Diana, 1979), em certa medida inaceitavelmente superficial e parcial, ao incluir apenas a produção cnsaística hispano-americana. 